Derecho civil 


\title{
¿El nacimiento no deseado podría constituir un daño indemnizable? (Diagnóstico prenatal fallido y responsabilidad médica en la jurisprudencia francesa.)
}

\author{
Luz Monge Talavera
}

Mediante el diagnóstico prenatal, la ciencia coloca al alcance de las parejas diversos medios técnicos destinados a conocer el estado de salud del embrión y del feto. En forma correlativa, parece legitimarse el deseo de no procrear niños que estén afectados por alguna enfermedad grave. El problema se presenta cuando el diagnóstico prenatal certifica de manera errónea la buena salud del feto y en el momento del nacimiento se descubre que porta una anomalía genética o una malformación grave. Surge, entonces, la pregunta: ¿el diagnóstico prenatal fallido es fuente de responsabilidad civil del facultativo? ¿Dónde radica la culpa? ¿Cuál es la naturaleza del daño? ¿Existe un vínculo de causalidad entre la enfermedad o discapacidad que afecta al niño y la negligencia atribuida al médico? Más allá: ¿la vida de un ser humano puede constituir un daño indemnizable? ¿Y qué se puede decir de la legitimidad del interés alegado?

Hasta hace algunos años el embrión era inaccesible, no había ningún medio para conocer su estado de salud, y el examen clínico de la mujer embarazada sólo permitía escuchar sus latidos cardiacos. A partir de los años setenta la ciencia descubre, poco a poco, los secretos de la vida intrauterina, permitiendo la visualización de la morfología del embrión o el feto, el estudio de su stock cromosómico y de su patrimonio genético. En la actualidad, desde los primeros estadios de la vida in utero es 
posible diagnosticar anomalías congénitas y hereditarias, así como la predisposición a desarrollar ciertas enfermedades en un futuro más o menos lejano.

Hoy podemos decir que las técnicas de diagnóstico prenatal han abierto "una ventana sobre el embrión" (Gavarini 1994: 227): se trata de un conjunto de prácticas médicas destinadas a detectar anomalías de cierta gravedad en el embrión o el feto. La Organización Mundial de la Salud (2009) precisa que "el diagnóstico prenatal se centra en la detección in utero de trastornos congénitos debidos a anomalías cromosómicas, defectos de un solo gen, trastornos multifactoriales y determinantes ambientales".

Estos procedimientos se inscriben en el cuadro de seguimiento del embarazo y forman parte de las políticas estatales de salud pública. La indicación más frecuente concierne a las parejas "a riesgo", es decir, donde la edad materna es avanzada (mujeres encinta, de más de 38 años), hay antecedentes familiares de casos de aberraciones cromosómicas o de enfermedades genéticas, o el embarazo muestra signos de alerta.

Los métodos utilizados permiten realizar un control completo del estado de salud del feto, pudiendo detectarse anomalías fetales multifactoriales (síndrome de Down, trisomías), defectos del tubo neural (espina bífida abierta, anencefalia, encefalocele), anomalías del sistema nervioso central (hidrocefalia), malformaciones abiertas de la pared abdominal, malformaciones cardiacas, tumores, labio leporino, entre otras (Huamán-Guerrero et al. 2007).

Las técnicas que se emplean se centran en la visión y el estudio de muestras. Entre las primeras, la más utilizada es la ecografía, ${ }^{1}$ instrumento de exploración que, gracias al ultrasonido, permite una visión detallada de la morfología externa e interna del feto. ${ }^{2}$ Se trata de un procedimiento sencillo, no invasivo y sin peligro. La precisión de resultados depende de la calidad del equipo ecográfico, de la experiencia del facultativo y de la edad gestacional en que se realiza el examen. ${ }^{3}$

Las técnicas invasivas (Huamán-Guerrero 2010) de diagnóstico prenatal utilizan el muestreo de tejidos del feto y de diversos constituyen-

1 Ultrasonografía o ecosonografía.

2 Es utilizada también para determinar con precisión la edad gestacional.

3 Las enfermedades o anomalías pueden ser visualizadas en diferentes momentos en el curso de la gestación. 
tes ovulares que permiten estudiar los cromosomas, las proteínas o los genes. Una de las más usadas es la amniocentesis, que consiste en la obtención del líquido amniótico que rodea al feto, mediante una punción en la cavidad uterina. Así, el estudio de las células fetales hace posible confirmar el diagnóstico de enfermedades metabólicas (mucoviscidosis) o anomalías cromosómicas (trisomía 21), entre otras. Otra técnica invasiva es la biopsia de vellosidades coriales, que recoge una muestra de células (vellosidades placentarias, cuya característica es que contienen todo el potencial genético del feto ${ }^{4}$ ) para estudiar el ADN, los cromosomas, las enzimas del feto ${ }^{5}$ y ciertos signos (llamados marcadores genéticos) de enfermedades, como, por ejemplo, el síndrome de Down y las hemoglobinopatías, entre otras. ${ }^{6}$

Gracias al análisis del ADN es posible diagnosticar también la simple predisposición a estados patológicos que se desarrollarán en la adolescencia, la edad adulta y, aun, durante la vejez (diabetes, cáncer, enfermedades cardiovasculares, enfermedad de Alzheimer). Resulta claro que los avances de la biología molecular abrirán nuevas vías para diagnósticos más precisos y cada vez más precoces.

Paralelamente, las parejas que desean procrear o que esperan un bebé son cada vez más sensibles a los progresos científicos; tanto, que el diagnóstico prenatal, en su forma más banal (la ecografía), constituye un camino casi obligado de toda mujer embarazada. Las ansias de los padres por obtener el "certificado" que les garantice que el hijo esperado está libre de anomalías o malformaciones han generalizado el recurso a la ecografía en el mundo entero. Publicaciones científicas remarcan el desarrollo inexorable de su uso en el conjunto de países en vías de desarrollo (Belizán 1998).

Cabe, sin embargo, remarcar que, si bien es cierto que la detección de una anomalía en el curso del embarazo podría facilitar planificar un

4 La muestra puede, sin embargo, contaminarse con células maternas y dar un resultado erróneo (Huamán-Guerrero 2010).

5 Permite diagnosticar cariotipo, sexo, trastornos metabólicos y presencia de infecciones intrauterinas por agentes como la rubéola, citomegalovirus, Toxoplasma gondii y el virus de la inmunodeficiencia humana (VIH-1).

6 Médicos peruanos señalan que la biopsia de vellosidades corial constituye en nuestro medio un procedimiento excepcional, utilizado en casos muy seleccionados, en los que hay una alta sospecha de anomalía cromosómica (HuamánGuerrero et al. 2007). 
tratamiento o una cirugía correctiva posnatal inmediata, el problema reside en que el desarrollo de los métodos de diagnóstico prenatal no va acompañado de descubrimientos comparables que permitan curar las enfermedades que se detectan. Rarísimas son las enfermedades que podrían ser tratadas in utero; ${ }^{7} \mathrm{y}$ si actualmente es posible practicar intervenciones quirúrgicas antenatales, la medicina fetal está lejos de aportar una solución a la generalidad de malformaciones o a las enfermedades genéticas.

Lo cierto es que, en el estado actual de la medicina, el diagnóstico prenatal no tiene una finalidad terapéutica. La identificación de una enfermedad genética o malformación no compatible con nuestros esquemas de "normalidad" conduce, en la gran mayoría de casos, a la aplicación de lo que la comunidad científica internacional denomina la "prevención secundaria de enfermedades", es decir, la eliminación de fetos enfermos. Diversos estudios, publicados por la propia OMS, concluyen destacando el aumento del número de interrupciones de embarazo debido a anomalías fetales constatadas mediante el uso de la ecografía (Neilson 2007).

En lo que concierne al Perú, es posible observar en la generalidad de ciudades del interior, y por supuesto en Lima, anuncios en los cuales se ofrecen ecografías fetales "de todo tipo": ecografía doppler color, ecografías $4 \mathrm{D}$, ecografías 3D, etc. En ellas se propone, en forma explícita, entre otras cosas, "el descarte de las principales malformaciones: síndrome de Down [sic]", 8 a lo cual se agrega, en letras más pequeñas, "servicios" como el siguiente: "manejo [sic] de malformaciones fetales". ${ }^{9}$ Obviamente, dado que se trata de malformaciones o de anomalías gené-

7 Trastornos del ritmo cardiaco fetal o anemia grave del feto.

8 <http://www.ecografiasperu.com/ecografias.php>. [Consulta: 27 de agosto del 2012.]

$9<$ <ttp://trujillo.infoisinfo.com.pe/ficha/centro_de_diagnostico_prenatal/36513>. [Consulta: 27 de agosto del 2012.]

"Somos el primer centro privado en nuestro país que ofrece un servicio especializado de diagnóstico y evaluación de la condición de su bebe cuando aún se encuentra dentro de su vientre, ofreciéndole la opción de un manejo adecuado y oportuno, maximizando de esta manera la posibilidad de lograr un feliz término de su embarazo" [sic]: <http://guialocal.com.pe/cenmef-centro-de-medicina-fetal. html>. [Consulta: 27 de agosto del 2012.] 
ticas, la terapia no inexiste y lo que se "oferta" es pura y simplemente la eliminación del embrión o feto afectado; y todo esto con la abierta anuencia de las autoridades.

Constatamos, entonces, que el diagnóstico prenatal no es un diagnóstico ordinario; su particularidad radica en que desemboca frecuentemente en la constatación de la existencia de una patología sin tratamiento, lo que origina un vínculo sistemático entre diagnóstico antenatal desfavorable e interrupción de gestación. Esta conjunción, como lo explica el profesor Jean Carbonnier (1985: 151), "coloca sobre el diagnóstico prenatal una sombra de tragedia y pone un germen de división entre las conciencias".

En efecto, las técnicas de diagnóstico prenatal se inscriben, hoy por hoy, en un proceso destinado a evitar el nacimiento de niños gravemente afectados, es decir, a garantizar a los padres la obtención de un resultado: el nacimiento de un "niño perfecto" o, por lo menos, libre de anomalía genética o malformación congénita. Esta situación se ve reconfortada por la tendencia (nacida en el derecho angloamericano) que aprehende la relación médico-paciente desde una perspectiva contractual de prestación de servicios, donde además de tener un precio en función de las leyes del mercado, la medicina es percibida como un bien de consumo cuyo pago del precio implica, en contrapartida, el "derecho" de esperar, y hasta de exigir, un resultado.

El problema se presenta en el caso de diagnósticos fallidos. Cuando el niño nace con una "anomalía" grave, a pesar de que los resultados del diagnóstico prenatal certificaron lo contrario, ¿la responsabilidad civil del facultativo se encuentra comprometida? ¿Podríamos hablar de pérdida de una chance de evitar el embarazo o el nacimiento? ¿Es posible, en nombre del infante nacido discapacitado o enfermo, invocar la pérdida de una chance de no nacer?

Constatamos que los sorprendentes progresos de las ciencias biomédicas nos colocan ante nuevas hipótesis de responsabilidad médica. Es posible examinar tres casos: primero, la no realización del diagnóstico prenatal por defecto de prescripción; enseguida, el carácter erróneo del diagnóstico realizado; y, finalmente, el consejo genético equivocado.

Bajo el prisma de los principios clásicos de la responsabilidad civil, corresponde examinar, antes que nada, si las condiciones de la responsabilidad están reunidas, es decir, dónde radica la culpa, cuál es la natu- 
raleza del daño, y el vínculo de causalidad de los une (ítem 1). Luego, a partir de allí, conviene voltear nuestras miradas hacia el análisis del derecho a la reparación (ítem 2 ).

\section{Las condiciones de la responsabilidad}

Desde hace aproximadamente veinte años, en diversos países han aparecido demandas dirigidas a obtener la reparación del daño que habría podido causar un diagnóstico prenatal errado. En este dominio es importante relevar cierta originalidad. Contrariamente a aquellas hipótesis en las cuales un diagnóstico correcto ulteriormente efectuado podría corregir el error inicial, aquí la terapia apropiada es, con frecuencia, inexistente. Por otra parte, el diagnóstico prenatal equívoco hace posible el nacimiento de un niño enfermo, cuando su realización fue prevista, precisamente, para evitarlo.

Otra particularidad que distingue el diagnóstico prenatal es que coloca al médico en la lógica de la "gestión de la incertidumbre". En ciertos casos el facultativo está en capacidad de asegurar la certeza del diagnóstico; en otros, se encuentra cercado en el terreno movedizo de la probabilidad: en efecto, ante la gravedad de la afección o la probabilidad de su aparición, los médicos solo pueden, en ocasiones, evaluar el riesgo en tanto elevado o mínimo. Igualmente, la interpretación de las imágenes de una ecografía fetal se subordina no solo a la experiencia adquirida por el profesional de salud y a la calidad de los equipos, sino también a la incertidumbre ligada a la posición del feto. En consecuencia, dados los riesgos inherentes a los métodos usados y al estado de desarrollo de las técnicas de exploración fetal, los médicos no están aún en capacidad de diagnosticar todas las anomalías. Estas particularidades trazan los límites de la obligación de información que corresponde al galeno, sobre quien pesa, naturalmente, la obligación de brindar al paciente una información adaptada a la materia.

En el lenguaje médico se utilizan los términos falso negativo y falso positivo en los casos de errores de diagnóstico. La expresión falso positivo alude a la afirmación de una afección que no existe en la realidad: el diagnóstico da lugar a una angustia injustificada en los padres y podría desembocar en una interrupción de la gestación ("inútil"); el error, sin embargo, pasará, en la generalidad de los casos, desapercibido. Contrariamente, el término falso negativo se refiere a la negación de una anoma- 
lía existente, que en realidad no fue diagnosticada: el resultado tranquiliza a los padres, quienes creen a su niño indemne; sin embargo, en el momento del nacimiento se revela una grave afección en el recién nacido. Aquí, el error es flagrante.

En este último caso, el error en el diagnóstico podría comprometer la responsabilidad del médico, siempre y cuando se pruebe, por supuesto, la existencia del vínculo de causalidad entre la culpa y el daño. Cabe, no obstante, observar que, en la materia que nos ocupa, la naturaleza del daño, y hasta su existencia real, son difíciles de caracterizar. Del mismo modo, como diversos autores lo hacen notar (Dekeuwer-Defossez s/f; Pierre 1995), el vínculo de causalidad resulta "problemático".

\subsection{La culpa}

El diagnóstico prenatal constituye un acto médico: a ese título, corresponde al médico una obligación de medios, no de resultado. El contrato médico obliga al profesional de salud - como lo señala el célebre arrêt Mercier ${ }^{10}$ - no a curar al paciente, sino solo a prodigarle cuidados concienzudos, atentos y conformes con los conocimientos actuales de la ciencia médica. ${ }^{11}$ El hecho, precisamente, de que en el dominio del diagnóstico prenatal estemos, con frecuencia, en el terreno del riesgo, confirma que la obligación del médico sólo puede ser de medios. ${ }^{12}$ Sin embargo, dada la complejidad de los análisis que el galeno debe practicar, se suele admitir que tiene la exigencia de un rigor particular en el ejercicio de su arte, así como en la apreciación e interpretación de todos los elementos propios y necesarios al establecimiento de un diagnostico científico. Le corresponde, también, la obligación (imperativa) de informar

10 Desde el 20 de mayo de 1936, con el célebre arrêt Mercier, la jurisprudencia francesa precisa el contenido de la obligación de los médicos.

11 Tratándose del ejercicio de la medicina, diversos autores opinan que la existencia del riesgo terapéutico y su aceptación por el paciente excluyen la calificación de obligación de resultado. En ese sentido, por ejemplo: Tourneau, Philippe le y Loïc Cadiet (1996: 284).

12 Por el contrario, tratándose de técnicas simples, no aleatorias, que obedecen a reglas estrictas, es posible afirmar que la obligación es de resultado. Es el caso del test de detección del sida, de la determinación del factor Rhesus, de la numeración de la fórmula sanguínea, de dosajes de urea, colesterol, creatinina, o glicemia. Aquí el biólogo procede a la adición de productos químicos invariables. Su trabajo, desprovisto de todo espíritu científico, es puramente manual y debe desembocar necesariamente en una solución exacta. 
a los padres de la existencia del riesgo de error inherente al diagnóstico prenatal que se va practicar.

Como en todo acto médico, en el cuadro del diagnóstico prenatal, la información que corresponde proporcionar al galeno debe ser "simple, leal, inteligible, adaptada" (Harichaux 1992: 438). En efecto, el profesional de salud debe velar siempre porque el mensaje sea bien entendido por el destinatario, lo que, es evidente, excluye la utilización de términos técnicos cuya comprensión sea inaccesible considerando el nivel cultural del paciente. El Código de Ética y Deontología del Colegio Médico del Perú (artículo 43) enfatiza esta obligación del profesional de salud estableciendo que le corresponde comprobar que la información ha sido entendida por el paciente, y solo entonces el consentimiento será considerado manifestado con autonomía. La obligación que pesa sobre el médico es proclamada, en sentido correlativo, como un derecho del paciente. El artículo 15 de la Ley General de Salud prevé que toda persona usuaria de los servicios de salud tiene derecho "a que se le dé en términos comprensibles información completa y continuada sobre su proceso, incluyendo el diagnóstico, pronóstico y alternativas de tratamiento".

Cabe precisar, entonces, que la obligación de información es tan extensa como complejo sea el acto médico. El diagnóstico prenatal exige al profesional de salud una información de alta calidad, clara y susceptible de ser comprendida por los padres.

Y es que, en realidad, el error en el diagnóstico no compromete, en principio, la responsabilidad del médico. Si el especialista utiliza los medios adecuados e interpreta los resultados según los conocimientos adquiridos por la ciencia, nada le puede ser recriminado. La responsabilidad yace en la culpa, no en el error.

Corresponde al magistrado examinar si el error se debe al hecho del alea inherente a las técnicas de diagnóstico antenatal, o si es posible reprocharle, al profesional, negligencia o ignorancia grave de los conocimientos actuales de la ciencia en el momento de despistar la anomalía. En ese sentido se pronuncia la jurisprudencia francesa, observando lo siguiente: "los dos médicos radiólogos estaban habilitados para practicar ecografías, que disponían de equipos recientes y habían consagrado a la realización del examen el tiempo necesario". ${ }^{13}$

13 Tribunal de Grande Instance de Draguignan, 1 de junio de 1995. Citado por Gombault (1996: 2, 816). 


\subsubsection{La no realización del diagnóstico prenatal}

Contrariamente, la culpa se caracteriza si el médico no prescribe la realización de los exámenes prenatales cuando debía proponer su realización. Es el caso de exámenes que forman parte del cuadro del seguimiento médico obligatorio del embarazo, en particular, la detección de patologías infecciosas maternas (rubéola o toxoplasmosis). En diversos países, como Francia, corresponde al médico ordenar el diagnóstico fetal cuando la embarazada tiene más de 38 años, cuando ya ha tenido un niño portador de alguna anomalía o cuando el embarazo manifieste signos de alerta.

En Francia, la falta de prescripción de la serología de la rubéola es reconocida de manera sistemática como una negligencia profesional. Así, el 16 de julio de 1991, la Corte de Casación francesa ${ }^{14}$ ha establecido la responsabilidad civil de tres médicos que en forma negligente habían obviado la prescripción de dicho examen. ${ }^{15}$ En el caso, los magistrados subrayaron un concurso de negligencias: el médico que había procedido al examen prenupcial no había ordenado la serología de la rubéola, a pesar de su carácter obligatorio; el generalista que certificó el embarazo en el primer mes, tampoco la había prescrito; $y$, a pesar de haber procedido a una detección de anticuerpos de la rubéola al segundo mes de embarazo, el ginecólogo tampoco advirtió ninguna consecuencia. La Corte estimó que los médicos habían faltado a su obligación de información, con lo que privaron a la mujer de la que resultaba necesaria para la protección inmunitaria contra la rubéola.

En el mismo sentido, también hay negligencia médica cuando el profesional omite prescribir exámenes complementarios si estos son necesarios para confirmar la interpretación dudosa de un primer diagnóstico: es lo que se puede observar en una resolución emitida por la Corte de Apelaciones de París, de 17 de febrero de 1989.16 Según los jueces parisinos, "actúa negligentemente el médico que, vistos los resultados de una serología de la rubéola practicada sobre una mujer encinta, no prescribe un segundo test que debía imperativamente realizarse dos

14 Gaz. Pal., 1992, 1, 152, note François Chabas.

15 Al nacer, el niño presentaba graves secuelas, propias de la rubéola que había infectado la madre al inicio de la gestación (catarata bilateral, malformación cardiaca y sordera).

16 D, 1989, somm., 316, obs. Jen Penneau. 
o tres semanas más tarde". En el caso, los médicos no habían ordenado un nuevo control serodiagnóstico a pesar de las recomendaciones del laboratorio, que había revelado una interpretación dudosa del primer test de la rubéola.

En otro asunto, conocido igualmente por los magistrados franceses el 22 de diciembre de 1994, se califica de "abstención negligente" que "infringe tanto su obligación contractual de consejo como sus obligaciones generales previstas en el Código de Salud Pública", el hecho de la omisión de una nueva ecografía que habría podido diagnosticar las malformaciones que afectaban al embrión. En el caso, los magistrados se sorprendieron de la actitud pasiva del ginecólogo, pues el radiólogo había recomendado la realización, tres semanas más tarde, de un nuevo control centrado en el corazón, debido a una defectuosa visualización de las estructuras cardiacas en el momento de la primera ecografía. El deceso del niño se produjo cinco días después de su nacimiento, a consecuencia de la malformación cardiaca que padecía. ${ }^{17}$

\subsubsection{La recomendación genética errónea}

Otro caso de responsabilidad puede igualmente derivarse de la orientación genética brindada por el especialista. El Código de Salud Pública francés dispone en el artículo L. 162-16 que el diagnóstico prenatal debe ser precedido de una consulta médica de orientación genética. En aplicación del citado dispositivo, los magistrados censuran al médico que omite tomar en consideración los elementos clínicos indispensables para establecer un diagnóstico científico.

Una resolución emitida por la Corte de Casación el 26 de marzo de $1996^{18}$ nos ofrece un ejemplo sobre el particular. La alta jurisdicción francesa ha establecido la responsabilidad de un médico especialista en genética que no había diagnosticado el carácter transmisible de una afección hereditaria. En el caso, la pareja - cuyo esposo era portador de trastornos neurológicos - había recurrido a un profesor de medicina, buscando un "consejo determinante y certidumbre respecto a la ausencia de riesgo de transmisión genética" de la misma discapacidad al hijo que deseaban concebir. El especialista había dado un consejo genético

17 Cardiopatía asociada a una comunicación entre la válvula mitral y el ventrículo izquierdo.

18 JCP, 1996, I, 3985, n. ${ }^{\circ}$ VI, obs. G. Viney. 
favorable, fundándose en la enfermedad de Little ${ }^{19}$ diagnosticada por los médicos tratantes; los futuros padres dedujeron, entonces, que no había ningún riesgo de transmisión. Sin embargo, cinco años después, la esposa dio a luz a un niño afectado de la misma discapacidad que el padre. La pericia concluyó que se trataba, en realidad, de una enfermedad heredo-degenerativa denominada de Strumpell-Lorrain, ${ }^{20}$ y criticó la negligencia del médico al haber ignorado el mismo problema neurológico existente en el hermano del marido.

\subsubsection{El carácter erróneo del diagnóstico}

Conviene precisar, de entrada, que en el error de diagnóstico la culpa se presenta también cuando un diagnóstico se establece a partir de análisis insuficientemente fiables. Los tribunales franceses consideran negligente el proceder del médico que proporciona un diagnóstico como seguro a pesar de las condiciones defectuosas de su realización. Considerando las consecuencias irreversibles que pueden desencadenarse de los resultados erróneos del diagnóstico prenatal, corresponde al especialista advertir a la mujer encinta la probabilidad de error inherente al análisis. Los magistrados remarcan el deber de información que incumbe al médico respecto al carácter falible de los exámenes.

El Tribunal de Grande Instancia de Montpellier ha estimado, con pertinencia, el 15 de diciembre de $1989,{ }^{21}$ que "el carácter incontestablemente erróneo del resultado del cariotipo no es en sí constitutivo de culpa". La infracción a la obligación de medios se caracteriza, según los magistrados, por el hecho de no haberse emitido reservas respecto al "grado de certeza que debía acordarse al examen". En el caso, el cultivo de líquido amniótico se había realizado en condiciones difíciles: la pericia señalaba que "el cultivo celular había sido lento y mediocre, habiendo permitido analizar solamente un pequeño número de mitosis de calidad media y con rupturas". Sin embargo, el laboratorio había proporcionado la respuesta: "cariotipo normal", esto es, la ausencia de índice característico de la trisomía 21; el nacimiento ulterior de un niño

19 Parálisis cerebral infantil.

20 El síndrome de Strumpell-Lorrain comprende un grupo de enfermedades de transmisión genética del sistema nervioso central, que producen espasticidad y paraplejia en los miembros inferiores.

21 JCP , 1990, II, 21556, obs. Jean-Pierre Gridel. 
afectado de mongolismo revelaría el carácter erróneo del diagnóstico. El tribunal increpa al laboratorio el hecho de haber presentado resultados aleatorios como desprovistos de toda posibilidad de error, cuando su obligación era informar, a los destinatarios del análisis, las dudas que envolvían la fiabilidad de dichos exámenes. ${ }^{22}$

Es evidente que el laboratorio conocía las dificultades que habían rodeado la realización del examen, por lo que le correspondía proceder a nuevos exámenes para aclarar su diagnóstico.

Más allá, si la determinación de la culpa no presenta mayores dificultades, en lo que se refiere al vínculo de causalidad, contrariamente, la polémica es viva.

\subsection{El vínculo de causalidad}

El problema de la determinación del vínculo de causalidad entre el diagnóstico prenatal fallido y el daño invocado es controvertido. El debate se inscribe alrededor de la pretensión destinada a demostrar la existencia de un vínculo de causalidad entre la discapacidad o enfermedad del niño y la negligencia atribuida al médico.

De acuerdo con el principio clásico, para que el profesional sea considerado responsable será necesario no solo probar que en el ejercicio de su arte procedió en forma culposa, sino también que el daño se deriva de manera directa y cierta de esa negligencia (Savatier, Auby y Pequignot 1956: 301). Siendo así, en la materia que nos ocupa, es evidente que el estado de salud del niño no se debe a la conducta negligente del profesional. La anomalía fetal es no solo preexistente al diagnóstico, sino que obedece a una etiología específica. Puede ser inherente al patrimonio genético del niño, como por ejemplo, las patologías cromosómicas (trisomía 21); puede ser igualmente consecuencia directa de un acontecimiento patológico infeccioso materno, viral (rubéola), parasitario (toxoplasmosis), bacteriano (listeriosis), etc.

En consecuencia, el carácter directo y cierto del vínculo de causalidad - principio fundador del derecho de la responsabilidad - entre la culpa y el daño invocado, simplemente, no existe. En la hipótesis de

22 En este asunto, los magistrados retienen la responsabilidad extracontractual del laboratorio, dado que las muestras necesarias para la realización de la amniocentesis habían sido recogidas en el centro de salud y luego enviadas a un laboratorio externo para su análisis. 
patologías cromosómicas, estas, al ser congénitas, son inseparables de la propia persona del niño. Tratándose de las infecciones maternas, el razonamiento es el mismo: la discapacidad que afecta al menor se debe, por ejemplo, a la rubéola que la madre padeció en el curso de la gestación.

Los magistrados franceses constatan que la trisomía que afecta al niño "es un hecho de la naturaleza y de ninguna manera puede vincularse al error en la calificación del cariotipo". ${ }^{23}$ De manera categórica, la Corte de Apelaciones de París sentencia que la reparación del daño invocado en nombre del menor debe ser desestimada, pues la culpa del médico "no tiene ningún vínculo de causalidad con el estado de salud del niño". 24

En efecto, la discapacidad del menor es anterior al error cometido por el laboratorio y, aun, a la ejecución de las obligaciones que corresponden el profesional.

Otra sentencia, también extraída de la jurisprudencia francesa, resalta en forma expresa la ausencia de vínculo de causalidad entre el diagnóstico prenatal fallido y la discapacidad del niño. Aquí, la demanda interpuesta en nombre del recién nacido increpaba al médico el hecho de no haber diagnosticado la rubéola contraída por la madre y, en consecuencia, de haber perdido "una chance de no nacer". Se invocaba así, en representación del niño, una suerte de "derecho a la eutanasia prenatal". ${ }^{25}$ Los magistrados subrayan que "el hecho de haber nacido no puede invocarse como fuente de daño", y que "si un ser humano desde su concepción es titular de derechos, no posee el derecho de nacer o no nacer, de vivir o no vivir, y su nacimiento o la supresión de su vida no puede ser considerada como una chance o una mala suerte, de la cual pueda extraer consecuencias jurídicas" ${ }^{\prime \prime}{ }^{26}$ de lo que se deriva que, aun enfermo de gravedad, el niño no puede quejarse de haber nacido.

Contrariamente, el análisis es opuesto cuando se invoca un vínculo causal entre la negligencia del médico y el daño ocasionado a los padres. En ese sentido se ha pronunciado la más alta instancia de la jurisdicción administrativa francesa en una resolución emitida el 14 de

23 JCP , 1990, II, 21556, obs. Jean-Pierre Gridel.

24 D, 1989, somm., 316, obs. Jean Penneau.

25 RTD civ, 1995, 863, obs. Jean Hauser.

26 Ibíd. 
febrero de 1997, 27 donde los magistrados toman en cuenta la voluntad de la madre, claramente expresada, de evitar un accidente genético y debido a cual había solicitado la realización de una amniocentesis. En este último caso, la información errónea que el diagnóstico proporciona y el daño invocado por la madre constituyen la piedra angular en la materia.

\subsection{El daño}

La existencia de un daño es la condición primera de toda acción en la materia. Aun cuando las malformaciones congénitas que le afectan no hayan sido detectadas por el examen prenatal, es necesario establecer, de entrada y firmemente, que el nacimiento de un niño (discapacitado) no puede ser en sí generador de daño: en realidad, si algún daño existe, este debe buscarse en "otra parte". La tendencia jurisprudencial dominante en Francia se refiere a la noción de pérdida de chances. Se invoca, igualmente, la existencia de un daño moral causado por el nacimiento de un niño gravemente afectado y, también, el daño material o económico representado por los gastos anormales ligados a la enfermedad del menor.

\subsubsection{La pérdida de chances}

En el dominio del diagnóstico prenatal fallido, la culpa del médico, constituida por la omisión de la prescripción de análisis, por la ausencia de información sobre el riesgo genético, así como por la falta de información acerca del riesgo de error en la detección de la anomalía fetal, priva a los padres de la información necesaria sobre el estado de salud real del feto. En ese sentido, la falta de información puede participar en la realización del daño y también constituirse en su causa directa.

En efecto, la negligencia médica impide a los futuros padres adoptar una decisión informada: les impide decidir libremente entre concebir o no concebir. También los induce falsamente a creer que el feto está indemne. Aquí, la supresión de la libertad de elegir está íntimamente ligada a la inexactitud del diagnóstico médico cuya función era proporcionar un resultado destinado a despejar una duda. Es posición dominante, pero controvertida, tanto en la jurisprudencia como en la doctri-

27 Gaz. Pal., 9 de marzo de 1997, p. 10, obs. Claudine Esper. 
na francesa, que el daño radica en la pérdida de chance de evitar la concepción o de rechazar la procreación.

Tratándose de profesionales altamente especializados, es legítimo confiar en el rigor de la realización, apreciación e interpretación de los exámenes. En todo caso, corresponde al profesional advertir al paciente sobre el carácter aleatorio o incierto de los resultados, sobre todo tomando en consideración que únicamente el médico conoce la manera y las condiciones en las cuales se efectúan los análisis y el grado de certidumbre que puede acordarse a los resultados.

Por otra parte, la certificación de la ausencia absoluta de riesgo, a pesar de que los resultados podían estar afectados de un margen de error, impide el recurso a un nuevo análisis, susceptible de evidenciar el error inicial.

Así, tratándose de los resultados erróneos de una ecografía, los magistrados franceses remarcan que las anomalías que afectaban al niño podían ser detectadas mediante una ecografía realizada conforme a las reglas del arte, y precisan que "las faltas cometidas por el doctor $\mathrm{X}$ privaron a los esposos de un derecho a la información, libertad fundamental de cada uno, independientemente del derecho que ellos habrían podido invocar" (Gombault 1996: 2, 816).

Respecto a los resultados erróneos de la serología de la rubéola, si bien es cierto que "ese control no podía prevenir las anomalías que irremediablemente afectaban al feto, hubiera permitido informar a la madre de la elevada probabilidad de que el concebido sea portador de graves afecciones propias de un aborto terapéutico". ${ }^{28}$ En ese mismo sentido, la Corte de Casación francesa subraya que la falta de información respecto de los riesgos causados por la rubéola "no permitió a los esposos tomar una decisión clara en cuanto a la posibilidad de recurrir a una interrupción terapéutica de la gestación" ${ }^{29}$ En un asunto similar, la misma instancia señala la existencia de un vínculo indudable entre la orientación genética errónea, dada cinco años antes del nacimiento, y la decisión de los padres de concebir un hijo: los magistrados precisan que "la falta cometida por el médico dando un consejo que no advertía a los esposos del riesgo de reaparición en su descendencia de los mismos

28 D, 1989, somm., 316, obs. Jean Penneau.

29 Gaz. Pal., 1992, 1, 152, note François Chabas. 
trastornos que afectaban al esposo, está en relación directa con la concepción del niño". ${ }^{30}$

\subsubsection{El daño moral}

Si desde el punto de vista ético es delicado considerar que el daño yace en el nacimiento de un niño (discapacitado o gravemente enfermo), sí cabe admitir que esa venida al mundo puede, en ciertas circunstancias, originar perturbaciones psicológicas y existenciales en los padres. Los especialistas señalan que, en una familia sin antecedentes particulares, el nacimiento de un niño portador de una grave afección es siempre un shock. Aun cuando, por cierto, todo embarazo comporta un riesgo, “¿qué padre imagina que podría tener un hijo que no será 'como los otros'?" (Briard 1992: 184).

Cuando el diagnóstico prenatal certifica indebidamente la buena salud del feto, los padres esperan con tranquilidad el parto; es recién en el momento del nacimiento que constatan bruscamente la existencia de una enfermedad o discapacidad grave que creían que no existía. Es posible que el drama emocional hubiera podido ser evitado si en forma oportuna se les hubiera informado sobre el estado de salud real del niño. En estos casos, para contribuir a una mejor aceptación de la anomalía, se recomienda el recurso a especialistas para que preparen psicológicamente a los futuros padres.

La consideración de ese trauma moral es acogida en forma clara por la jurisprudencia francesa (Gombault 1996: 2, 816). Los magistrados resaltan así los trastornos psicológicos en la madre (quien habría requerido tratamiento psicoterapéutico), junto con el "gran sufrimiento moral de los padres" a consecuencia del nacimiento de un niño afectado de trisomía $21 .{ }^{31}$ Hay cuidado en precisar que el daño moral radica, precisamente, en la falta de información. En ese sentido, se señala que los padres, "mantenidos en la ignorancia" de la malformación cardiaca que afectaba al feto, no habían podido prepararse ni preparar a los suyos respecto a la muerte del niño que esperaban. ${ }^{32}$

30 JCP, 1996, I, 3985, nº VI, obs. G. Viney.

31 Cour d'appel Versailles, 10 de junio de 1993. Citado por Gombault (1996).

32 TGI Metz, 22 de diciembre de 1994. Gaz. Pal., 1995, 2, 374, nota de Henri Vray. 


\section{El derecho a la reparación}

Si estimamos que el daño reside en la pérdida de la chance de rechazar la concepción, o aun la procreación, es necesario establecer que tal chance existía en el momento de los hechos y que se perdió como consecuencia de la inexactitud o la no realización del diagnóstico prenatal. En la eventualidad de que este último haya establecido de manera acertada la existencia de una "anomalía" grave, cabe preguntarse si la madre habría siempre, y en forma definitiva, optado por una interrupción terapéutica de la gestación y que dicha interrupción haya podido, en efecto, realizarse.

En el derecho nacional, una enfermedad grave e incurable que afecte al recién nacido no justifica, de plano, la realización de una interrupción terapéutica de la gestación, pues el Código Penal reserva esta hipótesis a aquellos casos en los que el embarazo pone en riesgo la vida o la salud de la madre. ${ }^{33}$ Sin embargo, la afirmación merece ciertas reservas a partir de la posición asumida por el Comité de Derechos Humanos de la ONU en el caso Karen Llantoy vs. Perú, el cual obliga a la realización de un acercamiento diferente sobre el particular (comunicación 1153/2003). Cabe recordar que el Comité precisa, en su Observación General número 20, que el derecho protegido en el artículo 7 del Pacto no solo hace referencia al dolor físico, sino también al sufrimiento moral de la madre. Es claro que el diagnóstico prenatal de una enfermedad grave e incurable que comprometa de modo irreversible la salud del feto puede causar un sufrimiento moral cierto en la madre y en su entorno.

Contrariamente, en numerosos países europeos y en Estados Unidos, la interrupción terapéutica de la gestación puede ser realizada en todos los casos en los cuales el feto sufra una afección particularmente grave. Las demandas destinadas a la reparación del daño que supuestamente se desprende del nacimiento de un niño que sufre una anomalía genética o malformación congénita son fuente de vivas discrepancias en el terreno doctrinal y jurisprudencial. En Francia, por ejemplo, la evolución jurisprudencial puede vislumbrarse desde dos etapas opuestas: la primera de ellas, antes del arrêt Perruche; y la segunda, después del arrêt Perruche. Este análisis nos permitirá abordar la evolución jurisprudencial y legislativa después del arrêt Perruche.

33 Aun en esas hipótesis, el aborto terapéutico no es posible a falta de la implementación de un protocolo en la materia. Ver Human Rights Watch (2008). 


\subsection{Evolución jurisprudencial antes del arrêt Perruche}

Interpelados los magistrados franceses acerca del particular, buscaron determinar si las condiciones exigidas para la realización de una interrupción terapéutica de la gestación estaban reunidas, y, en la hipótesis negativa, examinaron si la madre podía optar por una interrupción voluntaria del embarazo.

En la primera demanda interpuesta al respecto, los jueces requieren al perito precisar si la trisomía 21 que afectaba al recién nacido podía ser detectada en el momento de la realización de la amniocentesis, y si se cumplían, en el caso, las condiciones de fondo para una interrupción terapéutica de la gestación, es decir, si se trataba de una enfermedad grave e incurable. ${ }^{34}$

En otro asunto,, 35 en el cual la madre demandaba, por un lado, la reparación del daño que había sufrido a causa del nacimiento de su hijo discapacitado y, por otro, en nombre de su hijo, la reparación del daño sufrido por este a causa de su propia discapacidad, los magistrados remarcan que las malformaciones padecidas por el recién nacido no podían considerarse de "particular gravedad" y que la madre - encinta de 19 semanas en el momento de la realización de la ecografía - no podía legalmente recurrir a una interrupción voluntaria de la gestación. ${ }^{36}$ A pesar de que la ecografía no había diagnosticado las malformaciones de los miembros superiores que afectaban al feto, ${ }^{37}$ la resolución observa que el examen había sido practicado "según las reglas del arte", precisando además que no existía medida terapéutica, susceptible de aplicarse antes del nacimiento, que pudiera reducir o suprimir las malformaciones. Resulta evidente que, al no existir terapia apropiada, la noción de pérdida de una chance no puede ser invocada.

34 Tribunal administratif de Nice, 13 juillet 1989. El tribunal desestima la demanda observando la ausencia de culpa. Esta resolución fue declarada nula en segunda instancia (Cour administrative de Lyon, 21 de noviembre de 1991). Finalmente, el 14 de febrero de 1997, el Consejo de Estado retiene la culpa grave del centro hospitalario (Gaz. Pal., 9 de marzo de 1997, p. 10, obs. Claudine Esper).

35 Tribunal administratif de Strasbourg, 17 de julio de 1990: Gaz. Pal., 1991, 1, 52, concl. M. Herrs, Commissaire du Gouvernement; RD sanit. soc., 1991, 69.

36 En Francia, la interrupción voluntaria de la gestación puede realizarse dentro de las primeras doce semanas.

37 El niño estaba privado de ciertos dedos, del codo y estaba afectado de una malformación ósea. 
Así, la jurisprudencia francesa reconocía en forma unánime el derecho a una indemnización cuando la madre invocaba haber perdido una chance de someterse a una interrupción terapéutica de la gestación debido a la inexactitud del diagnóstico prenatal; contrariamente, las discrepancias imperaban en cuanto a la extensión del daño reparable. En algunos casos, bajo la premisa de que el estado de salud del recién nacido no presenta ningún vínculo causal con la negligencia del médico, la indemnización se limitó al aspecto moral del daño, es decir, al sufrimiento cotidiano de los padres a causa de la discapacidad severa del hijo; ${ }^{38}$ en otros casos se admitió la reparación íntegra tanto del daño material como moral padecido por los padres. Diversas resoluciones reconocen a estos, además de una renta mensual de por vida debido al daño material relativo a los gastos particulares de atención, salud y educación especializada necesarios - tratándose de niños discapacitados - , una indemnización específica a título de daño moral derivado de las perturbaciones en las condiciones de existencia que los padres de niños gravemente discapacitados deben afrontar. ${ }^{39}$

En forma paralela, la jurisprudencia francesa mostraba su hostilidad a toda demanda indemnizatoria en donde los padres alegaban que el daño yacía en el nacimiento de un niño discapacitado o afectado de alguna enfermedad grave. Igualmente, se rechazaba toda demanda promovida en nombre del recién nacido si se invocaba como único daño el hecho de su propia discapacidad. Apreciemos que en el fondo subyace la idea de que el único daño reparable es aquel que presenta un vínculo de causalidad directo con la negligencia del responsable.

Paralelamente, la Corte de Casación francesa concede una indemnización en aquellos casos en los que, debido a la negligencia del profesional, el recién nacido pierde la chance de nacer indemne. Es la hipótesis en que el error en el diagnóstico prenatal impide la aplicación de una terapia in utero que podría mejorar la salud o curar al feto. En un primer caso, el médico a cargo del seguimiento de la gestación no había ordenado los exámenes de rigor mensuales relativos a la toxoplasmosis y, en

38 Cour d'appel de Paris, 17 de febrero de 1989: D, 1989, somm., 316, obs. Jean Penneau.

39 TGI Montpellier, 15 de diciembre de 1989: JCP, 1990, II, 21556, obs. Jean-Pierre Gridel. Conseil d'État, 14 de febrero de 1997: Gaz. Pal., 9 de marzo de 1997, p. 10, obs. Claudine Esper. Cour d'appel de Paris, 17 de diciembre de 1993: D, 1995, somm., 98, obs. J. Penneau. 
consecuencia, no se realizó el tratamiento in utero correspondiente que, según la pericia, presentaba el $97 \%$ de chances de éxito. ${ }^{40}$

Igual razonamiento ha merecido la eventualidad en la cual, a causa del defecto de prescripción médica de la vacuna respectiva antes de la concepción, se le priva al niño de la posibilidad de evitar las consecuencias de la enfermedad contraída por la madre en el curso de la gestación. La máxima instancia de la jurisdicción judicial ${ }^{41}$ francesa estima como una negligencia profesional grave el hecho de no ordenar, durante el examen prenupcial, la serología de la rubéola, y deduce "la existencia de un vínculo de causalidad entre la abstención negligente del médico y la pérdida de una chance del niño de evitar las consecuencias de la rubéola contraída por la madre en los primeros meses del embarazo". Y a pesar de que la vacuna no es posible durante la gestación, junto al hecho de que no existe ninguna terapia in utero que permita paliar las consecuencias de la enfermedad, los magistrados consideran como responsables a los dos médicos encargados de atender el desarrollo del embarazo.

Fuera de esas hipótesis, evitar la enfermedad supone necesariamente la eliminación pura y simple del feto. Dado que en la gran mayoría de casos no existe terapia susceptible de aplicarse, el niño no tiene más alternativa que nacer discapacitado o simplemente no nacer. El diagnóstico erróneo no es la causa de la enfermedad que padece; podríamos decir, más bien, que es precisamente gracias al diagnóstico equívoco que el niño puede ver la luz del día y, por lo mismo, no es víctima de ningún daño reparable.

\subsection{El arrêt Perruche}

Ese razonamiento sereno y sólido de la jurisprudencia francesa fue dejado de lado en dos resoluciones pronunciadas el mismo día, el 26 de marzo de 1996, que - al decir de algunos autores - institucionalizan las famosas acciones en wrongfull life (Mémeteau 2000: I, 279) en Francia. Si bien es cierto este tipo de demandas indemnizatorias - en nombre de los padres (wrongful birth) o en nombre del propio recién nacido (wron-

40 Première chambre de la Cour de cassation, 3 de febrero de 1993. Pourvoir: n. ${ }^{\circ}$ 91-12.39

41 Cour de cassation, 16 de julio de 1991: D, 1991, 357, obs. J. Penneau; RD sanit. soc., 1992, 267, obs. Louis Dubois. 
gful life) - aparecieron en Estados Unidos, fueron posteriormente (entre los años 1985 y 1995) desestimadas por algunas cortes supremas y/o prohibidas por las legislaciones de algunos estados.

En las dos citadas resoluciones, la Corte de Casación francesa, además de reconocer la indemnización del daño personal ocasionado a los padres, admite la demanda indemnizatoria planteada en nombre del recién nacido, tendiente a la reparación del daño sufrido por este.

Recordemos que, en el primer caso, el niño era portador de una anomalía inscrita en su patrimonio genético. ${ }^{42} \mathrm{El}$ especialista había excluido, de manera errónea, del riesgo de transmisión genética de los trastornos neurológicos que padecía el marido, al hijo que la pareja deseaba concebir. Los magistrados consideran que el consejo genético equívoco presenta una relación directa con el deseo de concepción de la pareja y el posterior nacimiento del niño afectado de la misma enfermedad que el padre; correlativamente, se condena al médico a reparar tanto el perjuicio personal de los padres como el padecido por el infante.

En el segundo caso, denominado affaire Perruche, los padres demandaban, en nombre de su hijo nacido discapacitado, una indemnización correspondiente a las gravísimas secuelas de la infección de la rubéola contraída por la madre durante la gestación. ${ }^{43}$ Según los hechos, la hija de la pareja Perruche (de 4 años de edad) contrajo la rubéola en abril de 1982. Un mes después, la madre, aparentemente encinta, al presentar los mismos síntomas que la niña y enterada de los graves riesgos de la infección para el feto, habría manifestado su deseo de interrumpir la gestación. Los primeros análisis ordenados por el médico señalan que la señora Perruche no estaba inmunizada; para confirmar lo anterior, el facultativo ordena dos series suplementarias de análisis, cuyo resultado, en ambos casos, indica que la paciente sí lo estaba. Sin embargo, unos meses más tarde, la señora Perruche alumbra un niño (Nicolás) que desarrolló los graves trastornos neurológicos de la rubéola contraída por la madre durante el embarazo. ${ }^{44} \mathrm{El}$ informe pericial subraya el error del laboratorio y remarca la ausencia de sentido crítico del médico, quién debió ordenar una serie adicional de análisis.

42 JCP, 1996, I, 3985, n. ${ }^{\circ}$ VI, obs. G. Viney.

43 Conocidas con el nombre de síndrome de Gregg.

44 Sordera bilateral, retinopatía (ceguera en el ojo derecho y glaucoma) y cardiopatía, incontestablemente derivados de la rubéola congénita contraída durante su vida intrauterina. 
En primera instancia, el médico y el laboratorio son declarados "responsables del estado de salud de Nicolás". En segunda instancia, la Corte de Apelaciones de París, considerando que el facultativo había faltado a su obligación contractual de medios, lo condena a reparar el daño sufrido por la señora Perruche, pero desestima la indemnización solicitada en nombre del niño, pues remarca la ausencia de vínculo causal entre el daño y la negligencia del médico.

La Corte de Casación casa la resolución de vista y retiene tanto la responsabilidad del laboratorio como la del médico, y de sus respectivos seguros, apreciando que los errores en el diagnóstico y en el análisis habían inducido a los padres a creer equivocadamente que la madre estaba inmunizada, y que esos errores eran la causa generadora del daño sufrido por el recién nacido, derivado de la rubéola contraída por aquella durante la gestación. Agrega, además, que el médico no informó a la madre acerca del riesgo de malformaciones fetales ligadas a dicha enfermedad.

En virtud de la referida casación, los autos se remiten a la Corte de Apelaciones de Orléans para un nuevo pronunciamiento, instancia que en una resolución pronunciada el 5 de febrero de 1999, y calificada de "rebelde", se niega a admitir que Nicolás Perruche sufría un daño susceptible de reparación, derivado de la negligencia del médico y del laboratorio.

Incoada la acción contra esta última resolución, el affaire Perruche llega nuevamente a la suprema instancia francesa. Esta vez, la Asamblea Plenaria de la Corte de Casación, en sentencia emitida el 17 de noviembre del 2000,45 reafirma la indemnización del niño nacido discapacitado en razón de su propia discapacidad. Según la Corte, estando a que la negligencia del médico y del laboratorio en la ejecución del contrato con Mme. Perruche le han impedido ejercer su elección de interrumpir su gestación para evitar el nacimiento de un niño afectado de una discapacidad, el niño puede demandar la reparación del perjuicio derivado de esa discapacidad y causado por las referidas negligencias.

Es evidente que los magistrados no se interrogan más sobre el vínculo de causalidad entre la negligencia del profesional y la discapacidad del niño; lo plantean, más bien, entre el diagnóstico erróneo y el nacimiento. Ello significa la posibilidad de quejarse del hecho de haber

45 D, 2001, 332, nota D. Mazeaud y P. Jourdain; JCP, 2000, II, 10438, Rapport P. Sargos. 
nacido; dicho de otro modo, que la propia discapacidad puede constituir un daño que se deba reparar.

$\mathrm{Si}$, tradicionalmente, el vínculo de causalidad se descarta cuando se concluye que aun en ausencia de culpa el daño se habría producido, aquí, admitir la reparación del daño invocado en nombre del niño a causa de su propia discapacidad significa la afirmación de la existencia de responsabilidad fuera de toda relación causal: en efecto, no existe vínculo de causa a efecto entre la enfermedad que afecta al niño y el diagnóstico erróneo del médico. La generalidad de la doctrina francesa ha desaprobado la posición asumida por la Corte de Casación. Los comentarios más indignados resaltan el carácter inadmisible - respecto a los principios de la responsabilidad civil- de la indemnización de taras genéticas o de enfermedades de los que el recién nacido es naturalmente portador. ${ }^{46}$ Como remarca el profesor Jean Hauser, "no es la negligencia del médico lo que hizo nacer al niño en este estado. La culpa, si existe, solo ha contribuido a hacerlo nacer". ${ }^{47}$

Es claro que el médico no es responsable de la enfermedad del recién nacido ni, menos aún, del grado de discapacidad que lo afecta; la única culpa que se le puede imputar es la de de no haber diagnosticado una anomalía preexistente a su intervención. Si bien el nacimiento de un niño afectado de una enfermedad grave constituye una dura prueba para los padres, condenar al médico a indemnizar el daño material y moral invocado por padres y por niños discapacitados deja un sentimiento de injusticia.

Admitir tal indemnización lleva a preguntarse si algún día el debate girará en torno a determinar la existencia de "la pérdida de la chance de no vivir". En el fondo, se trata de saber si la vida es un don frente a la muerte o si esta última es preferible cuando la existencia es tan lamentable que no merece ser vivida. Sin duda, la respuesta está ligada a la concepción que cada uno pueda tener de la vida misma. Paralelamente, no se pueden dejar de lado las conclusiones de Pierre Sargos, consejero de la Corte de Casación francesa, quien insiste en el hecho de que lo que se indemniza no es la vida, sino el perjuicio que resulta de la discapacidad que pesará durante toda la existencia del niño y que le originará sufrimientos de diversa naturaleza.

46 Por ejemplo, Jean-Pierre Murat, JCP, 1996, I, 3946, n. ${ }^{o}$ III; Pierre Jourdain (2002).

47 RTD civ., 1996, 872. 
La sentencia de la Corte de Apelaciones de París, pronunciada el 11 de diciembre del 2002, que fija el monto de la indemnización en favor de Nicolás Perruche, marca el punto final de este affaire.

\subsection{Evolución jurisprudencial y legislativa después del arrêt Perruche}

Luego del affaire Perruche, la Corte de Casación francesa precisó su posición, en asuntos similares que le fueron sometidos, el 13 de julio del 2001 y el 28 de noviembre del mismo año. Las negligencias atribuidas a los médicos consistían en la ejecución e interpretación erróneas de ecografías fetales y en el incumplimiento de informar, estando obligados a ello, acerca de las anomalías detectables que privaron a la madre de la posibilidad de tomar una decisión libre y con conocimiento de causa respecto a la eventualidad de interrumpir la gestación. ${ }^{48}$

En el caso de un proceso examinado el 13 de julio del 2001, ${ }^{49}$ el infante había nacido con una malformación congénita del miembro superior derecho, que no era susceptible de tratamiento in utero. Sin embargo, flexibilizando de manera considerable la exigencia del vínculo de causalidad, la Corte de Casación francesa sentencia señalando que la culpa del facultativo es "la causa directa del nacimiento y de la incapacidad padecida por el recién nacido". Dentro de este razonamiento, la culpa del médico, encargado del seguimiento de la gestación, consistiría en el hecho de haber subestimado el precedente malformativo y no haber aportado el cuidado necesario al estudio morfológico del feto, lo cual habría inducido a los padres al error de creer que "su hijo era normal".

En el caso de otra sentencia, emitida igualmente el 13 de julio de $2001,{ }^{50}$ los exámenes ecográficos realizados en el curso de la gestación no habían detectado la presencia de espina bífida en el feto. Los magistrados revelan que "el niño puede ser indemnizado cuando, en razón de la falta del médico derivada de su obligación de información, era posible evitar, por un rechazo del proyecto parental, las consecuencias del nacimiento". La sentencia señala que, en razón de la culpa médica, el

48 Ver los desarrollos: Dorsner-Dolivet (2006: 157 y ss.); Welsch (2003: 209 y ss.).

49 Cour de cassation, Assemblée plénière, 13 de julio del 2001, N. ${ }^{\circ}$ de pourvoi: 98 19190; Bulletin 2001, A. P., N. ${ }^{\text {10 }}$ 10, p. 21.

50 Cour de cassation, Assemblée plénière, 13 de julio del 2001, N. ${ }^{\circ}$ de pourvoi: $97-$ 17359; Bulletin 2001, A. P., N. ${ }^{0} 10$, p. 21. 
niño habría perdido la chance de que la autorización para la realización de la interrupción de la gestación haya sido obtenida.

En otro asunto similar, sentenciado también el 13 de julio de 2001,51 se reprocha al facultativo no haber detectado, en la práctica e interpretación de la ecografía fetal, malformaciones en el miembro superior derecho, ni la ausencia completa del brazo izquierdo. ${ }^{52}$ Para los magistrados, el daño sufrido por el niño, nacido discapacitado, reside en la falta de información respecto a la morfología real de su futuro hijo, que impidió a los padres decidir una eventual interrupción de la gestación.

En suma, en los tres casos citados, la Corte se pronuncia en favor de la reparación demandada por los padres, pero rechaza indemnizar el perjuicio invocado en nombre del recién nacido.

En el mismo sentido de estas sentencias, esta vez en un caso resuelto el 28 de noviembre del 2001, ${ }^{53}$ la Corte de Casación francesa estima que existe un vínculo de causalidad entre la omisión de ordenar - en el curso de la gestación - la realización de un examen para la identificación de la trisomía 21 y la pérdida de la chance de tomar una decisión informada respecto al recurso a una interrupción voluntaria de la gestación. ${ }^{54}$ Si bien la anomalía genética que presentaba el recién nacido es independiente de la intervención del profesional, de nuevo, es el incumplimiento de la obligación de información que pesa sobre este lo que le obliga a reparar integralmente el perjuicio material de los padres derivado de los cuidados particulares que requiere el niño nacido con una discapacidad severa.

Una sentencia posterior, emitida asimismo el 28 de noviembre del $2001,{ }^{55}$ se aleja sensiblemente de las resoluciones antes citadas. En el

51 Cour de cassation, Assemblée plénière, 13 de julio del 2001, N. ${ }^{\circ}$ de pourvoi: $97-$ 19282; Bulletin 2001, A. P., N. ${ }^{\circ} 10$, p. 21.

52 Malformaciones que, según el perito, constituyen una "incapacidad considerable e incompatible con una vida normal".

53 Cour de cassation, Assemblée plénière, 28 de noviembre del 2001, N.o de pourvoi: 00-11197; Bulletin 2001, A. P., N. ${ }^{\circ}$ 15, p. 30.

54 En el caso, la madre, de 30 años, había dado a luz a un niño afectado de trisomía 21. Los padres reprochaban al médico encargado del seguimiento de la gestación el haber omitido prescribir un test para la detección de trisomía 21 (o una amniocentesis), a pesar de conocer de diversas dificultades presentadas por la madre en dos embarazos anteriores y de un antecedente familiar afectado de trisomía.

55 Cour de cassation, Assemblée plénière, 28 de noviembre del 2001, N. ${ }^{\circ}$ de pourvoi: 00-14248; Bulletin 2001, A. P., N. ${ }^{\circ}$ 16, p. 33. 
caso, el médico a cargo del cuidado de la gestación no había comunicado a la paciente, que luego trajo al mundo a un niño afectado de trisomía 21, los resultados alarmantes de un dosaje de "beta HCG", los que concordados con los exámenes ecográficos realizados justificaban la consulta con un especialista en genética. Según los magistrados, el incumplimiento del facultativo, quien no informó a la madre sobre los riesgos de anomalía fetal, está en relación directa con el nacimiento del niño portador de trisomía 21. Diferenciándose de las decisiones citadas, esta última resolución se pronuncia acogiendo la pretensión de la madre de indemnizar el perjuicio sufrido por el recién nacido, y precisa que ese perjuicio está constituido, ya no por la pérdida de chances, sino por la propia discapacidad que padece el menor, y que el principio de la reparación íntegra exige que sea completamente indemnizado. Esta decisión obviamente plasma en toda su magnitud la filosofía y, en consecuencia, el mandato del arrêt Perruche.

Ha sido necesaria la intervención del legislador para que se voltee la página y se deje atrás el arrêt Perruche. La indemnización íntegra del daño moral y material derivado del nacimiento de un niño gravemente discapacitado, luego de un error de diagnóstico prenatal que impide a la madre recurrir a interrumpir la gestación, ya no es posible.

Por Ley del 4 de marzo del 2002,56 denominada loi anti-Perruche, se ha establecido que "nadie puede prevalerse de una indemnización sólo por el hecho de su nacimiento". ${ }^{57}$ La misma ley dispone que la persona nacida discapacitada a causa de una falta médica, puede obtener reparación del perjuicio cuando el acto culposo ha provocado la discapacidad, la ha agravado o no ha permitido adoptar las medidas para atenuarla. Es el caso, entre otros, de una mal realizada interrupción de la gestación, a pesar de la cual el embarazo prosigue, pero originando una malformación en el niño. Es la hipótesis, también, de negligencias diversas que podrían originar un trauma en el infante durante el seguimiento del embarazo o en el momento del parto. En estos casos, la reparación debe ser integral, es decir, debe comprender tanto el daño moral como el material.

56 Ley 2002-303, Relative aux droits des malades et à la qualité du système de santé.

57 La ley contiene un título primero, denominado "Solidaridad hacia las personas discapacitadas". 
Contrariamente, al menos en Francia, si el niño nace afectado de una "anomalía" o discapacidad, a pesar de que los resultados del diagnóstico prenatal previeron lo contrario, ya no es posible reconocerle una indemnización a título del supuesto perjuicio derivado de su propia discapacidad. En aplicación estricta de la referida ley, podemos decir que la indemnización se excluye, pues el diagnóstico prenatal fallido no ha provocado ni agravado la discapacidad del menor, ni menos aún ha impedido atenuarla.

La Ley del 4 de marzo del 2002 aporta una solución diferente en cuanto a la indemnización relativa al perjuicio invocado por los padres a título personal. En efecto, cuando la responsabilidad de un profesional o de un establecimiento de salud está comprometida respecto a los progenitores del niño nacido con una discapacidad no identificada durante el embarazo, debido a una "culpa caracterizada", 58 los padres pueden demandar una indemnización, pero sólo a título del perjuicio que les causa a ellos mismos, el cual no incluye, naturalmente, las cargas particulares que se derivan de la discapacidad del menor. ${ }^{59}$ En consecuencia, la ley descarta la indemnización del supuesto daño económico o material, para restringir la indemnización al daño moral que un nacimiento de esa naturaleza podría causar a los padres.

Paralelamente, la misma ley establece que las cargas particulares que se derivan de la discapacidad del niño a lo largo de su vida son asumidas por la "solidaridad nacional", es decir, por el Estado. La Ley del 11 de febrero del 2005 prevé las modalidades de esta indemnización.

Sin embargo, el debate no está cerrado. Hace poco, luego de tres sentencias emitidas por la Sala Civil de la Corte de Casación, ${ }^{60}$ la máxima instancia de la jurisdicción administrativa francesa, el Consejo de Estado, ha precisado, en una resolución emitida el 24 de febrero del 2006, que las disposiciones de la Ley del 4 de marzo del 2002 son

58 Inexcusable.

59 En aplicación de la ley, quedan excluidas de la indemnización los gastos de educación especializada, la adquisición de una silla de ruedas, la asistencia de una persona para el cuidado del niño, el cambio de domicilio o su adaptación y, también, la renta por toda la vida del menor, acordada frecuentemente en estos asuntos.

60 De 24 de enero del 2006. 
aplicables a aquellas instancias en trámite, excepto cuando ha sido irrevocablemente decidido el principio de la indemnización. ${ }^{61}$

Más allá, cabe precisar que el nacimiento de un niño siempre es un acontecimiento portador de esperanzas, cuyas consecuencias, vinculadas a los imponderables de la vida, no pueden necesariamente preverse. ${ }^{62}$

\section{Bibliografía}

\section{Obras y artículos de revistas}

Abellán, Fernando (2001). Reproducción humana asistida y responsabilidad médica. Granada: Comares.

Belizán, José (1998). “Ecografía para evaluación fetal en el inicio del embarazo: Comentario de la BSR" (última revisión: 22 de setiembre de 1998). La Biblioteca de Salud Reproductiva de la OMS. Ginebra: OMS.

Briard, Marie-Louise (1992). “Le droit à l'enfant parfait: fantasme ou réalité", en Gros, François y Gérard Huber (dirs.). Vers un antidestin? Patrimoine génétique et droits de l'humanité. París: Odile Jacob.

Carbonnier, Jean et al. (1985). Actes du colloque Génétique, procréation et droit. París: Actes Sud - Hubert Nyssen.

Dekeuwer-Defossez, Françoise (s/f). "Interruption volontaire de grossesse". Rép. Pén. Dalloz 125. París.

Dorsner-Dolivet, Annick (2006). La responsabilité du médecin. París: Economica.

Dubois, Louis (1993). “La responsabilité civile du médecin à raison du diagnostic médical. La responsabilité civile du médecin. Presses universitaires d'Aix-Marseille.

61 Posición conforme a la emitida el 6 de octubre del 2205 por la Corte Europea de Derechos Humanos, que condena al Estado francés (en los casos Maurice y Draon) por violación del artículo primero del Protocolo N. ${ }^{\circ} 1$ de la Convención Europea de Derechos Humanos. En ambos casos, las jurisdicciones francesas habían desestimado, en aplicación retroactiva de la Ley del 4 de marzo del 2002, la indemnización solicitada en nombre del infante nacido discapacitado en razón de su propia discapacidad y el daño moral invocado por los padres.

62 CA Nimes, 13 de octubre de 1986: Juris Data n. ${ }^{0} 000842$. 
Gavarini, Laurence (1994). “Experts et législateurs de la normalité de l'être humain: vers un eugénisme discret", en Testart, Jacques (dir.). Le magasin des enfants. París: Gallimard.

Gombault, Nicolas (1996). "La responsabilité de l'échographiste du fait de l'absence de dépistage de malformations sur le fotus". Gaz. Pal.

Harichaux, Michelle (1992). “Diagnostic prénatal: les obligations et les risques", en Gros, François y Gérard Huber (dirs.). Vers un antidestin? Patrimoine génétique et droits de l'humanité. París: Odile Jacob.

Huamán-Guerrero, Moisés (2010). "Procedimientos invasivos en el diagnóstico prenatal". Revista Peruana de Ginecología y Obstetricia. Vol. 56, núm. 4.

Huamán-Guerrero, Moisés et al. (2007). “Diagnóstico prenatal de anomalías cromosómicas". Revista Peruana de Ginecología y Obstetricia. Vol. 53, núm. 3.

Human Rights Watch (2008). Tengo derechos, y tengo derecho a saber.

Jourdain, Pierre (2002). Le nouveau droit des malades. La fin de la jurisprudence Perruche. París: Litec.

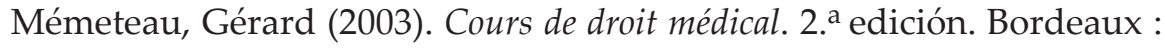
Les Etudes Hospitalières.

—. (2000). "L'action de vie dommageable". JCP.

Neilson, J.P. (2007). “Ecografía para evaluación fetal en el inicio del embarazo". Base de datos Cochrane de Revisiones Sistemáticas 2007. Número 4, artículo n. ${ }^{\circ}$ CD000182. DOI: 10.1002/14651858. CD000182. BSR La Biblioteca de Salud Reproductiva de la OMS. Ginebra: OMS.

Organización Mundial de la Salud (2009). Defectos congénitos. Informe de la Secretaría. Consejo Ejecutivo, 125 . $^{\text {a }}$ reunión, punto 5.4 del orden del día provisional. EB125/7, 14 de mayo del 2009.

Penneau, Jean (2004). La responsabilité du médecin. 3. ${ }^{a}$ edición. París: Dalloz.

Pierre, Philippe (1995). Médecine \& Droit.

Savatier, Auby y Pequignot (1956). Traite de droit médical. París: Librairies techniques. 
Thouvenin, Dominique (1995). La détection d'anomalies fæetales. París: CTNERHI.

Tourneau, Philippe le y Loïc Cadiet (1996). Droit de la responsabilité. París: Dalloz.

Viney, Geneviève (1997). L'indemnisation des accidents médicaux. París: LGDJ.

_. (1995). "Les grandes tendances des responsabilités professionnelles". La responsabilité médicale: de la faute au risque. Ecole Nationale de la Magistrature. Session de formation continue. ENM - 29 mai - 2 juin.

- (1995). Traité de droit civil. Introduction à la responsabilité. París: LGDJ.

Visintini, Giovanna (1999). Tratado de la responsabilidad civil. Tomo I: La culpa como criterio de imputación de responsabilidad. Buenos Aires: Astrea.

Welsch, Silvie (2003). Responsabilité du médecin. 2. ${ }^{a}$ edición. París: Litec.

\section{Resoluciones judiciales y administrativas francesas (por fecha)}

Cour de CASsation

- 16 de julio de 1991: Gaz. Pal., 1992, 1, 152, note François Chabas; D, 1991, 357, obs. J. Penneau; RD sanit. soc, 1992, 267, obs. Louis Dubois.

- 3 de febrero de 1993: Pourvoir: n. ${ }^{0}$ 91-12.39.

- 26 de marzo de 1996: JCP, 1996, I, 3985, n. ${ }^{\circ}$ VI, obs. G. Viney.

- 17 de noviembre del 2000: D, 2001, 332, note D. Mazeaud y P. Jourdain ; JCP, 2000, II, 10438, Rapport P. Sargos.

- 13 de julio del 2001, N. ${ }^{\circ}$ de pourvoi: 98-19190; Bulletin 2001, A. P., N.o 10, p. 21.

- 13 de julio del 2001, N. ${ }^{\circ}$ de pourvoi: 97-17359; Bulletin 2001, A. P., N. ${ }^{\mathrm{o}} 10$, p. 21.

- 13 de julio del 2001, N. ${ }^{\circ}$ de pourvoi: 97-19282; Bulletin 2001, A. P., N.o 10, p. 21. 
- 28 de noviembre del 2001, N. ${ }^{\circ}$ de pourvoi: 00-11197; Bulletin 2001, A. P., N. ${ }^{\circ} 15$, p. 30.

- 28 de noviembre del 2001, N. ${ }^{\circ}$ de pourvoi: 00-14248; Bulletin 2001, A. P., N. ${ }^{\circ} 16$, p. 33.

Conseil d'Etat

- 14 de febrero de 1997: Gaz. Pal., 9 de marzo de 1997, p. 10, obs. Claudine Esper.

Cour d'appel de Paris

- 17 de febrero de 1989: D, 1989, somm., 316, obs. Jean Penneau.

- 17 de diciembre de 1993: D, 1995, somm., 98, obs. J. Penneau.

- Tribunal de grande instance de Montpellier, 15 de diciembre de 1989: JCP, 1990, II, 21556, obs. Jean-Pierre Gridel.

- Tribunal de grande instance de Metz, 22 de diciembre de 1994: Gaz. Pal., 1995, 2, 374, note Henri Vray.

- Tribunal administratif de Strasbourg, 17 de julio de 1990: Gaz. Pal., 1991, 1, 52, concl. M. Herrs, Commissaire du Gouvernement; RD sanit. soc, 1991, 69. 